\title{
Analysis of patient load data for teams competing in the 2003 Cricket World Cup in South Africa
}

\author{
A Kilian (MB ChB) ${ }^{1}$ \\ R A Stretch (DPhil) $)^{2}$ \\ ${ }^{1}$ Private Practice, Port Elizabeth \\ ${ }^{2}$ Sport Bureau, Nelson Mandela Metropolitan University, Port Elizabeth
}

\begin{abstract}
Objectives. To evaluate the injury presentation data for all teams taking part in 10 warm-up matches and 46 matches during the 2003 Cricket World Cup played in South Africa, in order to provide organisers with the basis of a sound medical-care plan for future tournaments of a similar nature.

Methods. The data collected included the role of the injured person, the nature of the injury, whether the treatment was for an injury or an illness, whether the injury was acute, chronic or acute-on-chronic, and the prognosis (rest, play, unfit to play, sent home, follow-up treatment required). The medical personnel in charge of the medical support documented patient information which included the total number of patient presentations and the category of illness/injury.
\end{abstract}

Results. Ninety patient presentations (1.6 patient presentations per match) were recorded. The most common patient presentations were by the batsmen $(50 \%)$, followed by the bowlers $(29 \%)$ and all-rounders (17\%). Of the patient presentations, $53 \%$ were classified as injuries, while the remaining $47 \%$ were classified as illnesses. The patient presentations occurred in the early stages of the competition. The most common presentations were of an acute nature (63\%). The main injury pathology categories were trigger point injuries (10\%), and bruises / abrasions (10\%), while infection (29\%) was the main illness pathology.

Conclusions. The 2003 Cricket World Cup proved to be an ideal opportunity to collect data on international

\section{CORRESPONDENCE:}

\author{
R A Stretch \\ Sport Bureau \\ Nelson Mandela Metropolitan University \\ PO Box 77000 \\ Port Elizabeth \\ 6031 \\ Tel: 041-504 2584 \\ Fax: 041-504 1784 \\ E-mail: Richard.Stretch@nmmu.ac.za
}

cricketers participating in an intensive 6-week international competition; the epidemiological data collected should assist national cricket bodies and organisers of future Cricket World Cup competitions to predict participantrelated injury rates.

\section{Introduction}

In recent years findings on seasonal cricket injuries have been well documented in South Africa, ${ }^{10-16}$ Australia $^{5}$ and England. ${ }^{3}$ Variation in injury definitions and methods of data collection have limited the ability to draw comparisons relating to injury rate. However, the recently published consensus statement on the method of injury surveillance in international cricket should address this and allow meaningful comparisons to be made. ${ }^{6} \mathrm{~A}$ further area of concern and where there is a paucity of literature is that relating to cricket injuries while on international tours, specifically evidence describing the expected medical treatments at large tournaments such as the World Cup.

On the first tour (8 days) after South Africa's re-admission to international cricket, 8 of the 16 players, as well as the coach of the South African team received 31 treatments. ${ }^{9}$ Of the 14 injuries to the players, which were defined as conditions requiring medical or physiotherapy treatment, 7 (50\%) were bone/joint injuries, 3 were tendon injuries, 1 muscle, 1 ligament and 2 soft-tissue injuries, with the most commonly injured area being the lower limb (64\%). The injury rate was 1 injury per player.

On a 5-week international tour to South Africa, a total of 40 injuries were incurred by 16 players who received 166 treatments at an incidence rate of 2.5 injuries per player and 10.4 treatments per player. Of these, 24 were minor injuries, which took 3 or less treatments to heal, and 16 were major injuries, which took more than 3 treatments to heal and may have prevented participation in a match. The injuries were mainly bone/joint injuries $(N=14)$, muscle $(N=8)$, tendon $(N=6)$, ligament $(N=5)$ and 'other' $(N=7)$ injuries. ${ }^{7}$ Of the 40 injuries, $20 \%$ were injuries from the previous season that were re-aggravated.

The South African team to the World Cup in Australasia and then the subsequent tour to the Caribbean consisted of 14 players, with 2 additional players to learn and assist with practices. 
On the initial part of the tour, made up of 6 warm-up matches and 9 World Cup matches, the 16 players sustained 56 injuries, which were not defined, at an injury rate of 3.5 injuries per player. The most commonly injured area was the lower limb (50\%), comprising 16 bone / joint and 23 muscle injuries. $^{8}$

The Caribbean part of the tour consisted of 3 one-day internationals and a 5-day test match. Eleven of the 14 players sustained 15 injuries, which were not defined, at an injury rate of 1 injury per player. The lower limb (33\%) was the most commonly injured area, comprising 9 bone/joint and 3 muscle injuries. $^{8}$

On a 15-day tour of South Africa an English county team played 10 days of matches and trained on each of the other days. Thirteen of the 17 players on tour sustained 22 injuries, which were not defined, which required 92 treatments. Only 1 of the injuries prevented the player from playing. The lower limb was the most commonly injured area (45\%), with 10 bone/joints and 9 muscle injuries. ${ }^{1}$

The evidence shows that the number of injuries per player is proportional to the length of the tour and that lower-limb injuries as a result of fielding were the most common injuries on tours. ${ }^{2,8}$

The seasonal rate of injury to cricket players has been well documented over the past number of years, ${ }^{3,5,10-16}$ with the recent study on West Indies cricket $^{1}$ being the first to adhere to the internationally acceptable injury surveillance method and definition of injury. However, the literature on the injury rate of participants in a major cricket tournament is limited to only 1 team per tournament or tour., ${ }^{2,-9}$ Thus the purpose of this study was to evaluate the presentation data for all teams taking part in the 2003 Cricket World Cup played in South Africa, in order to provide organisers with the basis of a sound medical-care plan for future tournaments of a similar nature.

\section{Method}

The 2003 Cricket World Cup was held in February and March 2003, with 54 matches staged in South Africa, Zimbabwe and Kenya. Only the matches played in South Africa formed part of this study. The latter included 10 warm-up matches played prior to the competition, 34 first-round matches, 9 matches played during the Super 6 's and then the 2 semi-finals and the final (56 matches). The one-day international matches were played over 50 -overs and were either played as day matches (from $10 \mathrm{~h} 00$ to about 17h30) or as day-night matches (from $14 \mathrm{~h} 30$ to about $22 \mathrm{~h} 00$ ).

All the planning and procedures relating to the medical management of the spectators and players for all matches were the responsibility of the Medical Committee, with only the player data presented in this study. The Medical Committee held monthly meetings from January 2002 to May 2003 (16 meetings) and 3 seminars with the medical personnel prior to the start of the competition. Based on this a medical system was put in place in each city to cater for the needs of the players 24 hours a day.

Medical support was provided from the time that the teams arrived in the country, and the medical staff were available 24 hours a day. On match days a doctor was available to both teams for the full duration of the match. The necessary

\section{TABLE I. Demographic information and patient presentations at the 2003 Cricket World Cup}

\begin{tabular}{|c|c|c|c|c|c|c|c|}
\hline Country & $\begin{array}{l}\text { Warm-up } \\
(N)\end{array}$ & $\begin{array}{l}\text { First-round } \\
\text { (N) }\end{array}$ & $\begin{array}{l}\text { Super 6's } \\
(N)\end{array}$ & $\begin{array}{l}\text { Semi-final } \\
(N)\end{array}$ & $\begin{array}{l}\text { Final } \\
(N)\end{array}$ & $\begin{array}{l}\text { Tot: } \\
N\end{array}$ & $\begin{array}{l}\text { njuries } \\
\%\end{array}$ \\
\hline Australia & 2 & 8 & 2 & - & - & 12 & 13 \\
\hline Bangladesh & - & 3 & - & - & - & 3 & 4 \\
\hline Canada & 4 & 8 & - & - & - & 12 & 13 \\
\hline England & 1 & 10 & - & - & - & 11 & 12 \\
\hline Holland & - & - & - & - & - & - & - \\
\hline India & 2 & 5 & 3 & 2 & - & 12 & 13 \\
\hline Kenya & - & 2 & 3 & - & - & 5 & 6 \\
\hline Namibia & - & 1 & - & - & - & 1 & 1 \\
\hline New Zealand & - & 12 & 1 & - & - & 13 & 14 \\
\hline Pakistan & - & 1 & - & - & - & 1 & 1 \\
\hline South Africa & - & 3 & - & - & - & 3 & 4 \\
\hline Sri Lanka & 2 & 3 & 3 & - & - & 8 & 9 \\
\hline West Indies & 1 & 8 & - & - & - & 9 & 10 \\
\hline Zimbabwe & - & - & - & - & - & - & - \\
\hline Total & 12 & 64 & 12 & 2 & - & 90 & 100 \\
\hline$\%$ (total injuries) & 13 & 72 & 13 & 2 & - & 100 & \\
\hline Presentations/match & 1.2 & 1.9 & 1.3 & 1 & - & 1.6 & \\
\hline
\end{tabular}



TABLE II. Medical conditions and patient presentations at the 2003 Cricket World Cup

\begin{tabular}{|c|c|c|}
\hline & \multicolumn{2}{|c|}{ Patient presentations } \\
\hline & $N$ & $\%$ \\
\hline \multicolumn{3}{|l|}{ Number of patient presentations } \\
\hline One patient presentation $(1 \times 55)$ & 55 & 61 \\
\hline Two patient presentations $(2 \times 14)$ & 28 & 31 \\
\hline Three patient presentations $(3 \times 1)$ & 3 & 4 \\
\hline Four patient presentations $(4 \times 1)$ & 4 & 4 \\
\hline \multicolumn{3}{|l|}{ Chronicity of patient presentations } \\
\hline Injuries & 48 & 53 \\
\hline Acute & 30 & 33 \\
\hline Chronic & 3 & 3 \\
\hline Acute-on-chronic & 15 & 17 \\
\hline Illnesses & 42 & 47 \\
\hline Acute & 27 & 30 \\
\hline Chronic & 10 & 11 \\
\hline Acute-on-chronic & 5 & 6 \\
\hline \multicolumn{3}{|l|}{ Pathology category } \\
\hline Injuries & 48 & 53 \\
\hline Trigger points & 9 & 10 \\
\hline Bruises/abrasions & 9 & 10 \\
\hline Muscle strain & 6 & 7 \\
\hline Haematoma & 5 & 6 \\
\hline Acute fracture & 5 & 6 \\
\hline Tendinopathy & 4 & 4 \\
\hline Laceration & 3 & 3 \\
\hline Other & 7 & 7 \\
\hline IIInesses & 42 & 47 \\
\hline Infection & 26 & 29 \\
\hline Dermatology & 7 & 8 \\
\hline Other & 9 & 10 \\
\hline \multicolumn{3}{|l|}{ Prognosis } \\
\hline Continue to play & 51 & 57 \\
\hline Rest & 22 & 24 \\
\hline Unfit to play & 7 & 8 \\
\hline Follow-up treatment & 6 & 7 \\
\hline Team official & 4 & 4 \\
\hline
\end{tabular}

medical supplies and equipment were available at each medical station. An ambulance was available at each venue to transfer patients to hospital if necessary. Further, at least 1 hospital in each city was put on standby in the event of an emergency, with the normal daily staff on standby.

Data collected included the following: role of the injured person (batsman, bowler, all-rounder, wicket-keeper or official), nature of the injury, whether the treatment was for an injury or an illness, whether the injury was acute, chronic or acute-on-chronic, and the prognosis (rest, play, unfit to play, sent home, follow-up treatment required). The medical personnel in charge of the medical support documented patient information which included the total number of patient presentations and the category of illness/injury. In order to allow comparison with other cricket injury surveys the illness/ injury data as recommended in the consensus papers ${ }^{6}$ were classified using the OSICS (Orchard Sports Injury Classification System). ${ }^{4}$

\section{Results}

The results are shown in Tables I - IV. The results do not reflect any injuries and illnesses that may have been treated within the medical infrastructure of the teams, and thus the data reported could be an underestimation. However, in all probability these would have been minor day-to-day treatments such as for muscle aches and pains, headaches, etc.

Of the 14 teams participating only 2 teams did not record any patient presentations during the data collection period. Ninety patient presentations were recorded, with 86 recorded for players and 4 for officials. Of these, $13 \%$ occurring during the 10 warm-up matches, $72 \%$ during the 34 first-round matches, $13 \%$ during the 9 Super 6 's matches and $2 \%$ during the semi-finals. There were no patient presentations prior to or during the final. Thus there were 1.6 patient presentations per match for the 56 matches. Fifty-five players/officials recorded 1 patient presentation each, 14 recorded 2 patient presentations each, and the other 2 players recorded 3 and 4 patient presentations each.

The most common patient presentations were by the batsmen $(50 \%)$, followed by the bowlers $(29 \%)$ and allrounders $(17 \%)$. No wicket-keeper presented with a medical condition, while $4 \%$ of the patient presentations were by officials.

Of the patient presentations $53 \%$ were classified as injuries, while the remaining $47 \%$ were classified as illnesses. The most common presentations were of an acute nature $(63 \%)$, with the rest being chronic $(14 \%)$ and acute-onchronic (23\%).

The main injury pathology categories for patient presentations were trigger point injuries $(10 \%)$, bruises I abrasions (10\%), soft-tissue injuries including muscle strains $(7 \%)$, haematoma $(6 \%)$, and tendinopathy $(4 \%)$. The main illness pathology categories for patient presentations were infection (29\%), primarily consisting of otorespiratory, gastrointestinal and genitourinary infections, and dermatology (8\%).

Fifty-seven per cent of presenting patients were able to continue to play immediately, $24 \%$ were able to resume play again after a period of rest, while $7 \%$ needed further followup medical attention before being able to play again. Eight per cent were not able to take part in any further matches, and $4 \%$ of injuries involved officials. 


\begin{tabular}{|c|c|c|c|c|}
\hline & Warm-up / First round & Super 6's & Semi-final / Final & Total \\
\hline Injuries $(N)$ & 39 & 6 & 3 & 48 \\
\hline Head / neck & 5 & - & - & 5 \\
\hline Chest & 1 & - & - & 1 \\
\hline Back & 8 & - & - & 8 \\
\hline Shoulder /arm & 4 & 2 & - & 6 \\
\hline Hand / finger & 6 & 2 & 3 & 11 \\
\hline Groin / upper leg & 2 & 1 & - & 3 \\
\hline Knee / shin & 8 & 1 & - & 9 \\
\hline Ankle / foot & 5 & - & - & 5 \\
\hline IIInesses $(N)$ & 39 & 3 & - & 42 \\
\hline URTI & 11 & 2 & - & 13 \\
\hline Dermatology & 7 & - & - & 7 \\
\hline Gastrointestinal & 5 & 1 & - & 6 \\
\hline Eye & 3 & - & - & 3 \\
\hline UTI & 3 & - & - & 3 \\
\hline Fatigue/insomnia & 3 & - & - & 3 \\
\hline Bee sting/tick-bite & 3 & - & - & 3 \\
\hline Mouth sores & 2 & - & - & 2 \\
\hline Hernia & 2 & - & - & 2 \\
\hline Total $(N)$ & 78 & 9 & 3 & 90 \\
\hline
\end{tabular}

\section{Discussion}

The primary findings here indicate that the patient presentations occurred in the early stages of the competition, batsmen were more susceptible to injury/illness than bowlers, and illnesses accounted for nearly half of the participant presentations. Most injuries were of an acute or acute-onchronic nature.

In preparation for the tournament there is a need to develop the team, and to achieve this most teams take part in pre-World Cup matches in order to try out various combinations and to give players the opportunity to develop experience in pressure situations. This increase in training and match-play volume and intensity in order to ensure that the team arrives at the World Cup with the correct batting and bowling combinations may be one of the predisposing injury factors. This increased workload could result in players sustaining minor injuries that escalate into more serious injuries when participating in the high-intensity World Cup matches. As the World Cup is held only every 4 years, the desire among players to take part in the event may result in their not disclosing 'niggles' or minor injuries in order to ensure selection. In order to avoid this situation, the preWorld Cup schedule of teams needs to be planned carefully, with the players not arriving over-trained.
The findings here indicate that batsmen were more susceptible to injury/illness. This is different to the literature on seasonal risk of injury ${ }^{3,5,10-16}$ which shows that bowlers, particularly fast bowlers, are at the greatest risk of injury. Because of the format of the World Cup tournament, bowlers are not likely to sustain chronic over-use injuries due to the limit of 10 overs per match for each bowler and the relatively long time between matches which allows the bowlers to recover fully. However, the larger number of acute injuries would be as a result of the intense nature of the World Cup matches, particularly from a batting and fielding perspective. When batting the players have to take quick runs, often for extended periods, predisposing them to acute soft-tissue injuries.

Illnesses accounted for nearly half of the participant presentations, with infections constituting the primary cause of these participant presentations. During the initial part of the tour the players are generally busy trying to acclimatise to foreign conditions while continuing with an intense programme of fitness, skill and match preparation, and as a result may be susceptible to various infections. One way to reduce the risk may be for clothing manufacturers to adapt the playing clothing to meet this need. Bowlers, on the other hand, are able to take off and put on their jerseys between overs and their high-intensity bowling spells. 
TABLE IV. Chronicity of injuries and illnesses, role, and stage of the 2003 Cricket World Cup when injury was sustained

\begin{tabular}{|c|c|c|c|c|}
\hline & Warm-up / First round & Super 6's & Semi-final / Final & Total \\
\hline \multicolumn{5}{|l|}{ Acute } \\
\hline Batsmen & 15 & 2 & 1 & 18 \\
\hline Bowlers & 5 & 1 & & 6 \\
\hline All-rounders & 4 & 1 & 1 & 6 \\
\hline \multicolumn{5}{|l|}{ Chronic } \\
\hline Batsmen & 3 & - & - & 3 \\
\hline Bowlers & - & - & - & - \\
\hline All-rounders & - & - & - & - \\
\hline \multicolumn{5}{|c|}{ Acute-on-chronic } \\
\hline Batsmen & 3 & & & 3 \\
\hline Bowlers & 5 & 1 & 1 & 7 \\
\hline All-rounders & 3 & 2 & & 5 \\
\hline
\end{tabular}

Collection of data on medical conditions and injuries in cricket players is difficult due to the unique nature of cricket which is played over an extended match period, with the players often on long tours, both at home and abroad, without an accompanying doctor.

The 2003 Cricket World Cup proved to be an ideal opportunity to collect data on international cricketers participating in an intensive 6-week international competition, and the epidemiological data collected should assist national cricket bodies and organisers of future Cricket World Cup competitions to predict participant-related injury rates.

\section{REFERENCES}

1. Mansingh A, Harper L, Headley S, King-Mowatt J, Mansingh G. Injuries in West Indies cricket 2003-2004. Br J Sports Med 2006; 40: 119-23.

2. Morton J. Cricket injuries of the Northamptonshire County Cricket team during a 15 day tour of Natal. South African Journal of Sports Medicine 1992; 7: 18 - 20.

3. Newman DA. Prospective survey of injuries at first class counties in England and Wales 2001 and 2002 seasons. In: Stretch RA, Noakes TD, Vaughan CL, eds. Science and Medicine in Cricket. Cape Town: comPress, 2003: 343-50.

4. Orchard J. Orchard sports injury classification system (OSICS). In: Bloomfield J, Fricker P, Fitch K, eds. Science and Medicine in Sport. 2nd ed. Melbourne: Blackwell, 1995, 674 - 8.

5. Orchard J, James T, Alcott E, Carter S, Farhart P. Injuries in Australian cricket at first class level 1995/1996 to 2000/2001. Br J Sports Med 2002; 36: $270-5$.

6. Orchard JW, Newman D, Stretch R, Frost W, Manshing A, Leious A. Methods for injury surveillance in international cricket. J Sci Med Sport 2005; 8: 1 -14.

7. Smith C. Sports injuries encountered on a five week international cricket tour. South African Journal of Sports Medicine 1990, 6 (1): 10 - 5.

8. Smith C. Cricket injuries of the South African team at the World Cup and in the Caribbean: The physiotherapy perspective. South African Journal of Sports Medicine 1991; 7: 20 - 4.

9. Smith C. Cricket injuries while on tour with the South African team in India. South African Journal of Sports Medicine 1992; 7(1): 4 - 8.

10. Stretch RA. Injuries to South African cricketers playing at first-class level. South African Journal of Sports Medicine 1989; 4: 3-20.

11. Stretch RA. The incidence and nature of injuries in club and provincial cricketers. South African Journal of Sports Medicine 1993; 83: 339-41.

12. Stretch RA. The incidence and nature of injuries in schoolboy cricketers. $S$ Afr Med J 1995; 85: 1182-4

13. Stretch RA. Incidence and nature of epidemiological injuries to elite South African cricket players. South African Journal of Sports Medicine 2001a; 91: 336-9.

14. Stretch RA. The incidence and nature of epidemiological injuries to elite South African cricket players over a two-season period. South African Journal of Sports Medicine 2001b; 8:17 - 20.

15. Stretch RA. Cricket Injuries: a longitudinal study of the nature of injuries to South African cricketers. Br J Sports Med 2003; 37: 250 - 3

16. Stretch RA, Venter DJL. Cricket injuries: A longitudinal study of the nature of injuries to South African cricketers. South African Journal of Sports Medicine 2003; 15: 4 - 8.

\section{UPMARKET HEALTH CENTRE REQUIRES A DOCTOR}

Healthjunction, an established multi-disciplinary Health Centre in the City Bowl seeks an energetic, proactive doctor to set up practice. Join our professional and passionate team comprising physiotherapists, biokineticists and pilates instructors. We service an upmarket and active clientele.

Full time or sessional option. Call Cathy on 0824653745 or e-mail cathy@healthjunction.co.za 